\title{
Ein Tipp zu Tipps und Tricks
}

Dankward Höntzsch, Florian Gebhard, Michael Raschke, Ulrich Stöckle

\section{Machen Sie mit!}

Jeder weiß mindestens 1 oder 2 Tipps und/oder Tricks in Ihrem OP oder auf Station.

Machen Sie doch mit: Ein Bild und 3 Sätze als Konzept reichen. Wie bei einem Selfie und einem Satz bei Twitter ${ }^{\circledR}$ oder WhatsApp ${ }^{\circledR}$.

Das Team vom OP-Journal hilft Ihnen.

Der Tipp oder Trick ist nie zu einfach oder banal. Operationen und Behandlungen brauchen den wissenschaftlichen Hintergrund. Dazu sind die Beiträge im Heft.
Aber vor allem brauchen wir Anleitungen für handwerkliche Anwendungen. Egal auf welchem Gebiet lebt das Handwerk von Tipps und Tricks.

Dazu gibt es diese Rubrik:

Für Sie und von Ihnen bitte in Zukunft gefüllt!

Wir warten:

Dankward Höntzsch, Florian Gebhard, Michael Raschke, Ulrich Stöckle
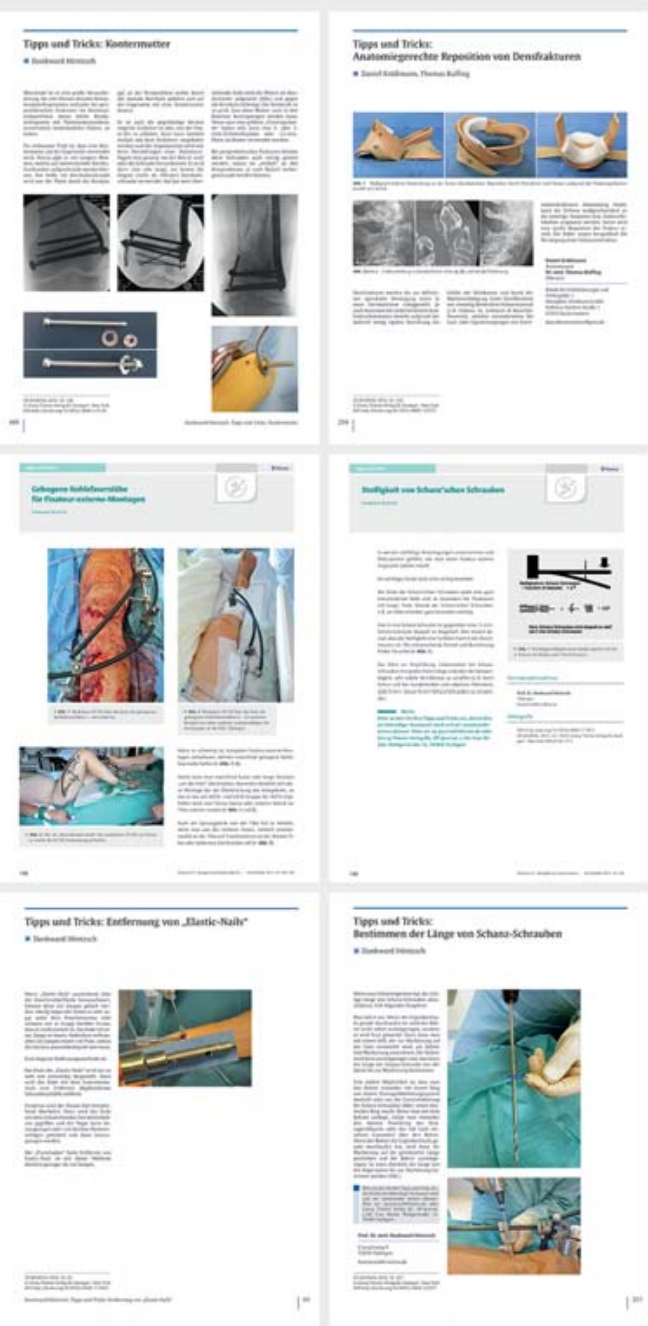

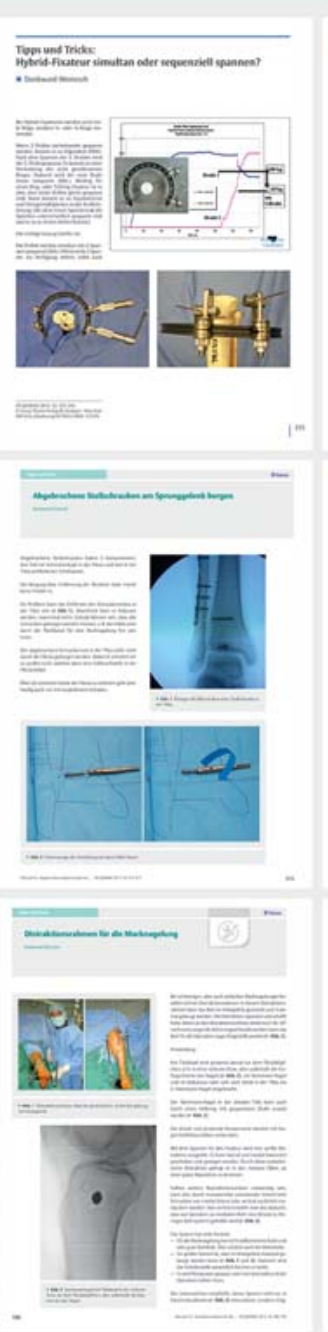

